\title{
Evaluation of the Effects of Transcutaneous Electrical Nerve Stimulation (TENS) On the Whole Salivary Flow Rate in Healthy Adult Subjects -A Clinical Study
}

\author{
Vikas Singla ${ }^{1 *}$, Thimmarasa V.B. ${ }^{2}$, Parvathi Devi ${ }^{3}$, Neha Singla4 ${ }^{4}$, Neha Aggarwal ${ }^{5}$ \\ ${ }^{1}$ Dental Officer, Army hospital, Kurukshetra, India \\ 2Professor, Department of Oral Medicine and Radiology, Rishiraj College of Dental Sciences \& Research Centre, Bhopal, India \\ 3Professor, Department of Oral Medicine and Radiology, Teerthankar Mahaveer Dental College, Moradabad, India \\ 4Private Practitioner, Zirakpur, India \\ ${ }^{5}$ Senior Lecturer, Manav Rachna Dental College, Faridabad, India
}

\section{*Corresponding Author}

Dr. Vikas Singla

\author{
Article History \\ Received: 25.06.2019 \\ Accepted: 11.07 .2019 \\ Published: 30.07 .2019
}

\begin{abstract}
Background and Objective: Saliva is a critical fluid necessary for oral health. Xerostomia and salivary gland hypofunctioning are associated with advancing age, autoimmune diseases, head and neck radiation, smoking and recreational drug usage. Palliative management of xerostomia includes wetting agents such as ice chips, saliva substitutes, increased water intake, applying lip balm, chewing sugar free gum or sucking sour sugar-free lemon drops, paraffin, and citric acid containing lozenges and rinses. Systemic agents stimulate the salivary flow but have unfavourable side effects. Therefore, this study was undertaken to evaluate the effects of transcutaneous electrical nerve stimulation (TENS) on the whole salivary flow rate in healthy adult subjects. Study Design: Seventy three healthy adult subjects with no history of salivary gland disorder were enrolled in the protocol. TENS electrode pads were placed externally on the skin overlying the major salivary glands. Unstimulated whole saliva was collected for 5 minutes into a graduated test tube. The TENS unit was then activated and stimulated saliva was collected for another 5 minutes in a separate graduated test tube. Results: Sixty nine out of seventy three demonstrated increased whole salivary flow when stimulated via TENS unit. Four subjects showed a decrease in the salivary flow. The mean unstimulated salivary flow rate was $0.479 \pm 0.152$ $\mathrm{ml} / \mathrm{min}$ while under stimulated condition it was $0.724 \pm 0.189 \mathrm{ml} / \mathrm{min}$, thereby showing a percentage increment of $51.1 \%$ following TENS application. Statistical analysis of flow rates showed the difference to be significant $(p<0.001)$ Conclusion: The TENS unit was highly effective in stimulating the whole salivary flow rate in healthy adult subjects. A further study in patients with xerostomia secondary to various local and systemic causes is required.
\end{abstract}

Keywords: Xerostomia, stimulated saliva, TENS

\section{INTRODUCTION}

Saliva is a critical fluid necessary for oral health. There is an old axiom which states "You will never miss water till the well runs dry". How true this is, especially for saliva; the fact is, a world without saliva is a world without pleasure....like living in a drought $[1,2]$. Saliva has many important physiologic functions as it maintains neutral $\mathrm{pH}$, contains calcium and phosphate that are essential for maintaining enamel mineralization. As a lubricant, it aids in speech, swallowing, clearing of debris and reduces the friction [3]. In edentulous individuals, it is required for the retention of complete dentures and the protection of the denture bearing tissues [4]. Saliva contains salivary $\operatorname{lgA}$ and thus aids in oral immunology but medications, radiation therapy and systemic conditions can decrease salivary function [3].

Saliva is regarded as one of the important factors in regulating oral health, with respect to both the volume produced and the constituents it contains. The functional disturbances of the salivary glands can cause a reduction in salivary flow and subjective dryness [5]. This increases a risk for rampant caries, increased plaque formation, opportunistic fungal infections, mucositis, difficulty in eating and swallowing, malnourishment and oral pain [3]. The saliva circulating in the mouth, at any given time, is termed whole saliva

Copyright @ 2019: This is an open-access article distributed under the terms of the Creative Commons Attribution license which permits unrestricted use, distribution, and reproduction in any medium for non commercial use (NonCommercial, or CC-BY-NC) provided the original author and source are credited. 
[2]. The three major salivary glands (parotid, submandibular and sublingual) contribute to 90 percent of the mixed fluid in the mouth; minor salivary glands that are scattered throughout the mouth contribute to the remaining 10 percent of the mixed fluid. Food debris, microorganisms and gingival crevicular fluid are other components of whole saliva. Saliva is composed of approximately 99 percent water and 1 percent proteins and salts [6].

Parotid glands consist entirely of serous acini, submandibular and sublingual glands contain mucous and serous acini, and minor salivary glands contain predominantly mucous acini [7]. The submandibular glands are the major contributors to resting (unstimulated) saliva and the parotid glands are the major contributors to stimulated saliva. The contribution of sublingual glands to unstimulated and stimulated whole saliva is low [6].

Xerostomia is used to describe the subjective sensation of oral dryness resulting from severe reduction of salivary flow rate [8]. However, it does not equate consistently with hyposalivation [9]. It is a common clinical phenomenon present in about $40 \%$ of adults over the age of 50 years [10]. It can be caused by several medications without actual reduction in the salivary flow. The major cause of xerostomia, however, is objectively assessed by salivary gland hypofunction which can be attributed to various systemic diseases as sjogren syndrome, rheumatoid arthritis, systemic lupus erythematosus etc[6]. The other causes include radiotherapy and chemotherapy of head and neck cancers, medications (anti-cholinergic drugs, bronchodilators, decongestants, diuretics, protease inhibitors, lithium etc.), psychogenic disorders, dehydration, decreased mastication etc[1, 11, 12].

Palliative management of xerostomia includes wetting agents such as ice chips and saliva substitutes. Other measures can include increasing water intake, applying lip balm, chewing sugar free gum or sucking sour sugar-free lemon drops, paraffin, and citric acid containing lozenges and rinses. The addition of a humidifier to the room may be beneficial. Patients need to be counseled to avoid mouth breathing, caffeine, smoking, carbonated beverages, alcohol based drinks and mouthwashes, and changing or discontinuing drugs causing dry mouth [2, 3]. The systemic sialogogues like pilocarpine, anethole trithione, bromhexine and cevimeline are used to stimulate the salivary flow. Acupuncture has brought about improvement in xerostomic and healthy patients [2, 10]. A mucin spray and herbally based agent with vitamin supplements were also found useful against xerostomia [12]. Among the disadvantages of these therapies, however, are that the effects are short lived and application needs to be frequent. Adverse effects have also been reported such as profuse sweating, urinary frequency, rhinitis and dyspepsia [10]. All the above mentioned treatment modalities have met with the limited success.

Electrostimulation is also a technique to increase the salivary output in patients with xerostomia. The procedure uses an electrostimulation device to increase the salivary production from existing glandular tissue [13]. Transcutaneous electrical nerve stimulation (TENS) is a well known physical, non-invasive and non-pharmacological method for the electrical stimulation of the nerves through electrodes applied to the skin [14]. Electrostimulation by TENS to produce saliva has also been studied in the past and studies showed moderate promising results. Research in this area has been sparse and hence, this study was undertaken to evaluate the effects of transcutaneous electrical nerve stimulation on the whole salivary flow rate in healthy adult subjects and also to compare the flow rate between the unstimulated saliva and saliva stimulated with TENS.

\section{MATERIALS AND METHOD}

The present study was conducted in the Department of Oral Medicine and Radiology, Rama Dental College Hospital and Research Centre, Kanpur, to evaluate the effects of TENS on the whole salivary flow rate in healthy adult subjects. A total of 73 healthy adult subjects including both males and females aged between 21 - 50 years, who voluntarily enrolled for the study was selected. The subjects were explained the procedure involved in the study and their consent was obtained. In all, extreme care was taken to selectively exclude the patients with a history of salivary gland pathology and psychiatric disorders, patients with active pacemaker, hearing aid, defibrillator and cochlear implants, patients suffering from any systemic disease or any autoimmune disorder, patients with history of head and neck radiation, patients using any medication, pregnant females and subjects under 18 years of age. All the 73 subjects ( 36 males and 37 females) were explained the need and design of the study and asked to refrain from eating, drinking, chewing gum and smoking. They were also told about the importance of oral hygiene procedures like brushing and mouth rinsing several times with distilled water, at least one hour prior to the appointment.

The TENS unit employed for this study was RELIEF TENS-II. The settings of the TENS unit were as follows: the pulse rate was fixed at $50 \mathrm{~Hz}$, the pulse duration was fixed at $250 \mu \mathrm{sec}$ and the unit was in normal mode. The surface electrode pads were placed externally on the skin overlying the parotid, sub-mandibular and sublingual glands with the TENS unit in the "off" position (Fig 1). The subjects were made to sit in an upright position with the head inclined forward and with minimal body and oro-facial movements. They were asked to swallow saliva first and then instructed to stay motionless, so that the saliva would collect passively in the anterior region of the floor of the mouth. With low forced spitting, unstimulated saliva was then collected every minute for 5 minutes in a graduated test tube fitted with a funnel. The TENS unit was then activated for 5 minutes. The pulse rate was fixed at 50 $\mathrm{Hz}$ and the amplitude was gradually increased to a maximum tolerable level of patient. At optimal intensity (the maximum intensity that the subject perceived to be comfortable), stimulated saliva was collected for 5 minutes in a separate graduated test tube and the flow rate was compared with the unstimulated salivary flow rate. A log of adverse effects was kept during and after treatment. The salivary flow rate was calculated by dividing the amount of collected saliva (volume in $\mathrm{ml}$ ) by the duration of collection period (five minutes) and 
compared. Per individual subject, any increase in the salivary flow with electrostimulation was considered a positive finding. The chi square test was used to study the proportional differences between the age groups. The " $\mathrm{t}$ " test was used to compare the differences in salivary flow rate with respect to gender (independent samples " $t$ " test). Differences owing to the change in condition were studied using paired "t" test. All the tests were performed using Statistical Package for Social Sciences (SPSS) Version 15.0 Statistical Analysis Software.

\section{RESULTS}

Sixty nine out of seventy three responded positively to TENS therapy. The mean salivary flow rate under unstimulated condition was found to be $0.479 \pm 0.152 \mathrm{ml} / \mathrm{min}$ while under stimulated condition it was found to be $0.724 \pm 0.189 \mathrm{ml} / \mathrm{min}$, thereby showing a percentage increment of $51.1 \%$. Statistically, the increase was found to be significant $(p<0.001)$ (Table 1, Graph 1). In four patients, the salivary flow was decreased with the application of TENS.

Amongst males the mean flow of saliva was higher as compared to females, in both unstimulated and stimulated experiments, however, the difference between two genders was not significant statistically $(p>0.05)$ for either experiment (Table 2 , Graph 2). Statistically significant increment in mean saliva flow was seen after stimulation in both the genders $(p<0.001)($ Table 3 , Graph 3). Both under stimulated and unstimulated conditions the mean salivary flow rate of younger age group was significantly higher as compared to that of older age group $(p<0.05)$ (Table 4, Graph 4). In both the age groups, the mean flow rates increased significantly following stimulation $(p<0.001)$ (Table 5 , Graph 5).

Table-1: Mean salivary flow rate of subjects under stimulated and unstimulated conditions

\begin{tabular}{|c|c|c|c|c|c|}
\hline S. No. & Condition & $\begin{array}{c}\text { No. of } \\
\text { subjects }\end{array}$ & $\begin{array}{c}\text { Mean salivary } \\
\text { flow rate }\end{array}$ & SD & SEM \\
\hline 1. & Unstimulated & 73 & 0.479 & 0.152 & 0.018 \\
\hline 2. & Stimulated & 73 & 0.724 & 0.189 & 0.022 \\
\hline
\end{tabular}

"t"=14.237; p<0.001 (Paired "t"-test used)

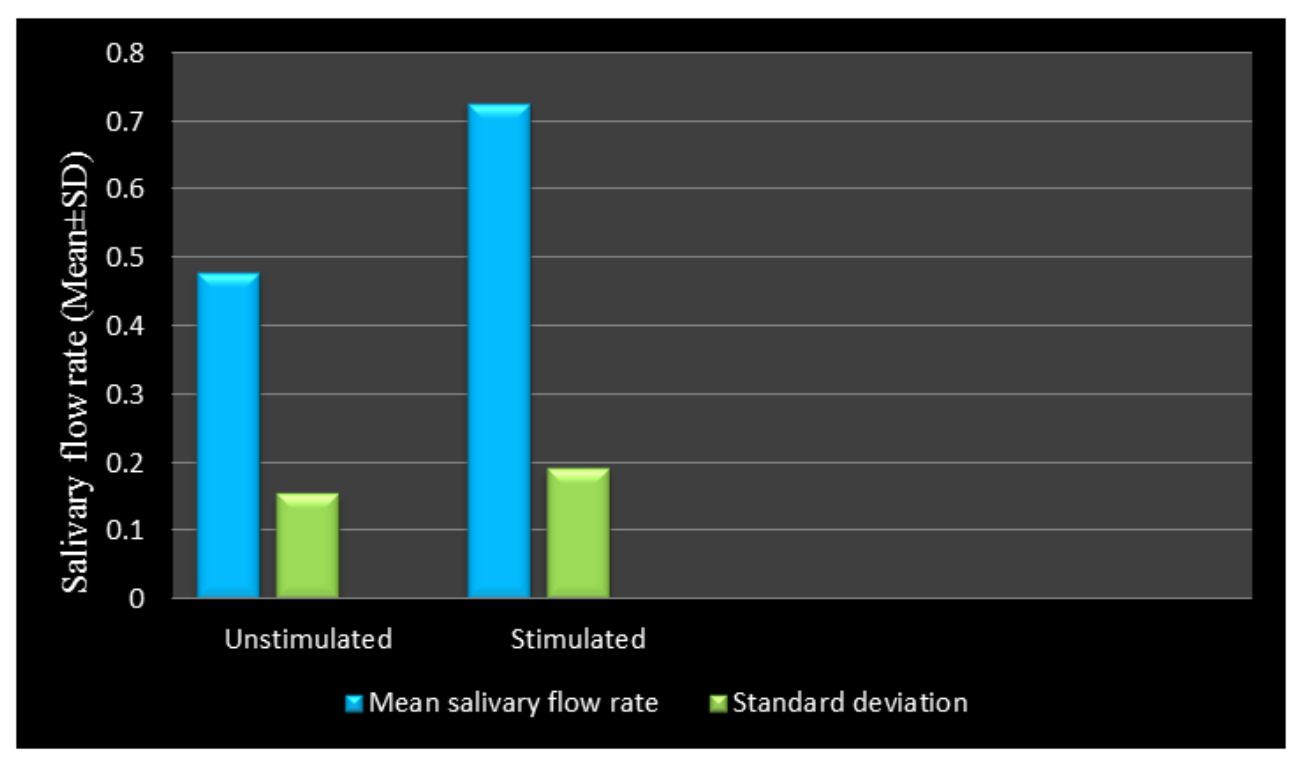

Graph-1: Mean salivary flow rate of subjects under stimulated and unstimulated conditions

Table-2: Gender wise comparison of mean salivary flow rate of subjects under stimulated and unstimulated conditions

\begin{tabular}{|c|c|c|c|c|c|c|c|}
\hline \multirow[t]{2}{*}{ S.No. } & \multirow[t]{2}{*}{ Condition } & \multirow[t]{2}{*}{ Gender } & \multirow[t]{2}{*}{$\begin{array}{c}\text { No. of } \\
\text { subjects }\end{array}$} & \multirow[t]{2}{*}{$\begin{array}{c}\text { Mean } \\
\text { salivary } \\
\text { flow rate }\end{array}$} & \multirow[t]{2}{*}{ SD } & \multicolumn{2}{|c|}{$\begin{array}{c}\text { Significance of } \\
\text { gender wise } \\
\text { difference }\end{array}$} \\
\hline & & & & & & "t" & "p" \\
\hline \multirow[t]{2}{*}{1.} & \multirow[t]{2}{*}{ Unstimulated } & Female & 37 & 0.456 & 0.122 & \multirow[t]{2}{*}{1.172} & \multirow[t]{2}{*}{0.245} \\
\hline & & Male & 36 & 0.500 & 0.177 & & \\
\hline \multirow[t]{2}{*}{2.} & \multirow[t]{2}{*}{ Stimulated } & Female & 37 & 0.690 & 0.194 & \multirow[t]{2}{*}{1.569} & \multirow[t]{2}{*}{0.121} \\
\hline & & Male & 36 & 0.759 & 0.179 & & \\
\hline
\end{tabular}




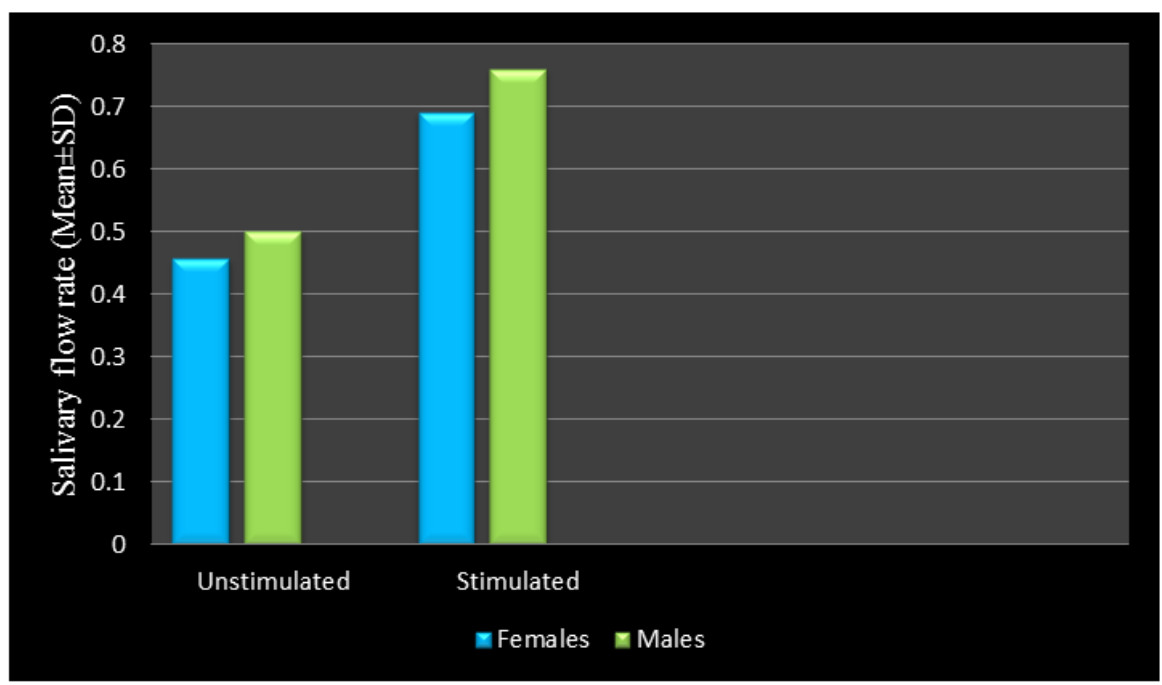

Graph-2: Gender wise comparison of mean salivary flow rate of subjects under stimulated and unstimulated conditions

Table-3: Condition wise comparison of mean salivary flow rate of subjects in two genders

\begin{tabular}{|c|c|c|c|c|c|c|c|}
\hline \multirow[t]{2}{*}{ S.No. } & \multirow[t]{2}{*}{ Gender } & \multirow[t]{2}{*}{ Condition } & \multirow[t]{2}{*}{$\begin{array}{c}\text { No. of } \\
\text { subjects }\end{array}$} & \multirow[t]{2}{*}{$\begin{array}{c}\text { Mean } \\
\text { salivary } \\
\text { flow rate }\end{array}$} & \multirow[t]{2}{*}{ SD } & \multicolumn{2}{|c|}{$\begin{array}{c}\text { Significance of } \\
\text { difference due to } \\
\text { conditioning Paired } \\
\text { "t"-test }\end{array}$} \\
\hline & & & & & & "t" & "p" \\
\hline \multirow[t]{2}{*}{1.} & \multirow[t]{2}{*}{ Female } & Unstimulated & 37 & 0.46 & 0.12 & \multirow[t]{2}{*}{9.580} & \multirow[t]{2}{*}{$<0.001$} \\
\hline & & Stimulated & 37 & 0.69 & 0.19 & & \\
\hline \multirow[t]{2}{*}{2.} & \multirow[t]{2}{*}{ Male } & Unstimulated & 36 & 0.50 & 0.18 & \multirow[t]{2}{*}{10.503} & \multirow[t]{2}{*}{$<0.001$} \\
\hline & & Stimulated & 36 & 0.76 & 0.18 & & \\
\hline
\end{tabular}

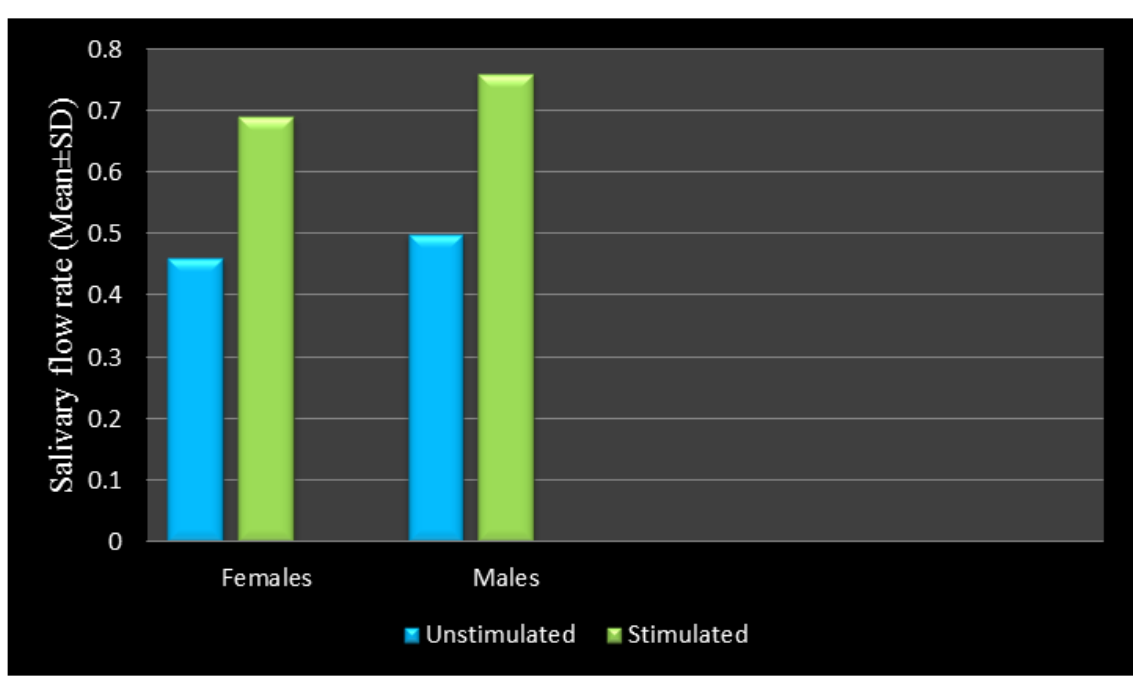

Graph-3: Condition wise comparison of mean salivary flow rate of subjects in two genders

Table-4: Age wise comparison of mean salivary flow rate of subjects under stimulated and unstimulated conditions

\begin{tabular}{|c|c|c|c|c|c|c|c|}
\hline \multirow[t]{2}{*}{ S.No. } & \multirow[t]{2}{*}{ Condition } & \multirow[t]{2}{*}{ Age } & \multirow[t]{2}{*}{$\begin{array}{c}\text { No. of } \\
\text { subjects }\end{array}$} & \multirow[t]{2}{*}{$\begin{array}{c}\text { Mean } \\
\text { salivary flow } \\
\text { rate }\end{array}$} & \multirow[t]{2}{*}{ SD } & \multicolumn{2}{|c|}{$\begin{array}{l}\text { Significance of } \\
\text { age wise } \\
\text { difference }\end{array}$} \\
\hline & & & & & & "t" & "p" \\
\hline \multirow[t]{2}{*}{1.} & \multirow[t]{2}{*}{ Unstimulated } & $\leq 35$ & 38 & 0.52 & 0.18 & \multirow[t]{2}{*}{2.353} & \multirow[t]{2}{*}{0.021} \\
\hline & & $>35$ & 35 & 0.44 & 0.10 & & \\
\hline \multirow[t]{2}{*}{2.} & \multirow[t]{2}{*}{ Stimulated } & $\leq 35$ & 38 & 0.78 & 0.18 & \multirow[t]{2}{*}{2.499} & \multirow[t]{2}{*}{0.015} \\
\hline & & $>35$ & 35 & 0.67 & 0.18 & & \\
\hline
\end{tabular}




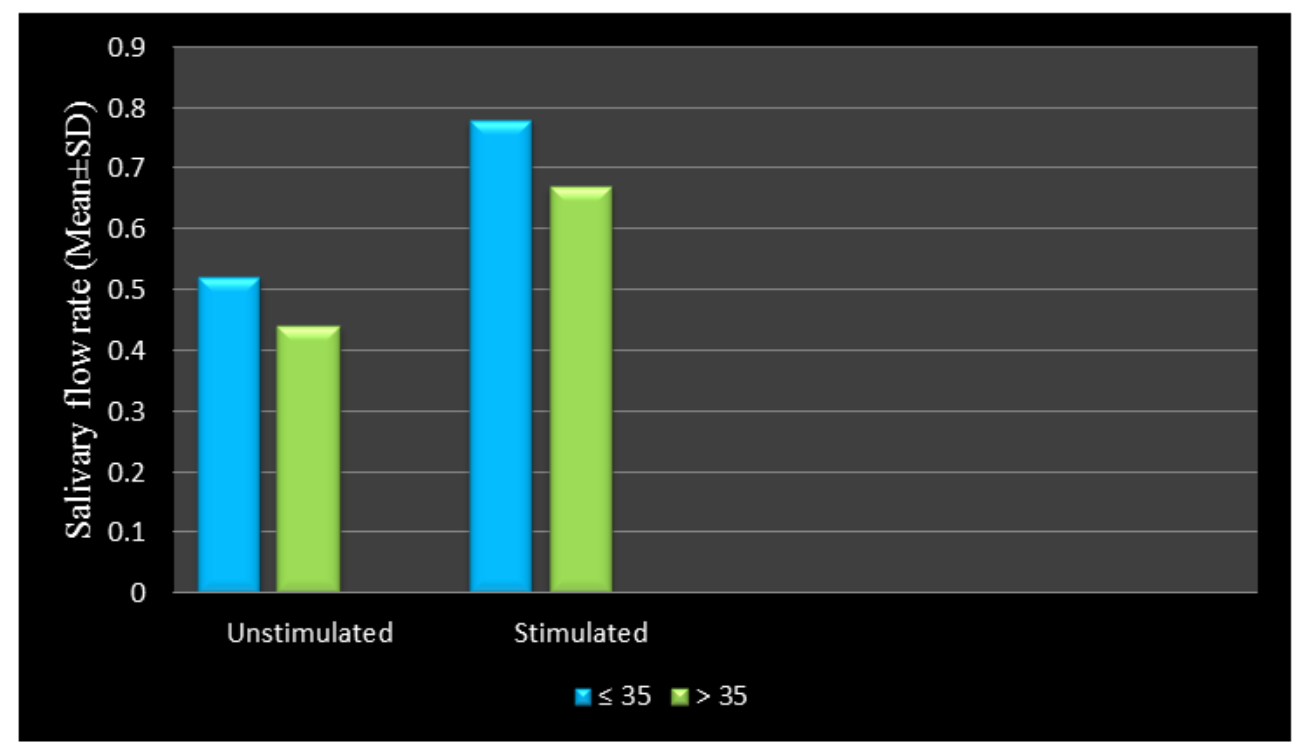

Graph-4: Age wise comparison of mean salivary flow rate of subjects under stimulated and unstimulated conditions

Table-5: Condition wise comparison of mean salivary flow rate of subjects for different age groups

\begin{tabular}{|c|c|c|c|c|c|c|c|}
\hline \multirow[t]{2}{*}{ S.No. } & \multirow[t]{2}{*}{ Age } & \multirow[t]{2}{*}{ Condition } & \multirow[t]{2}{*}{$\begin{array}{c}\text { No. of } \\
\text { subjects }\end{array}$} & \multirow[t]{2}{*}{$\begin{array}{c}\text { Mean } \\
\text { salivary flow } \\
\text { rate }\end{array}$} & \multirow[t]{2}{*}{ SD } & \multicolumn{2}{|c|}{$\begin{array}{l}\text { Significance of } \\
\text { difference due to } \\
\text { conditioning } \\
\text { Paired "t"- test }\end{array}$} \\
\hline & & & & & & "t" & "p" \\
\hline \multirow[t]{2}{*}{1.} & \multirow[t]{2}{*}{$\leq 35$} & Unstimulated & 38 & 0.52 & 0.18 & \multirow[t]{2}{*}{10.190} & \multirow[t]{2}{*}{$<0.001$} \\
\hline & & Stimulated & 38 & 0.78 & 0.18 & & \\
\hline \multirow[t]{2}{*}{2.} & \multirow[t]{2}{*}{$>35$} & Unstimulated & 35 & 0.44 & 0.10 & \multirow[t]{2}{*}{9.922} & \multirow[t]{2}{*}{$<0.001$} \\
\hline & & Stimulated & 35 & 0.67 & 0.18 & & \\
\hline
\end{tabular}

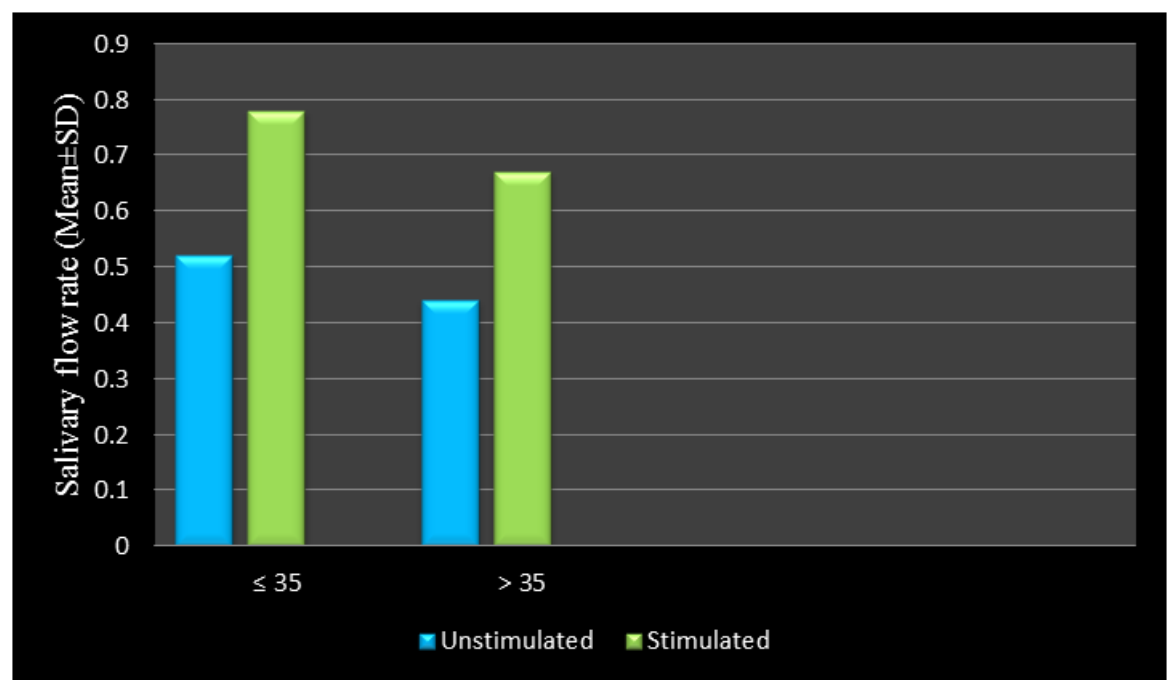

Graph-5: Condition wise comparison of mean salivary flow rate of subjects for different age groups 


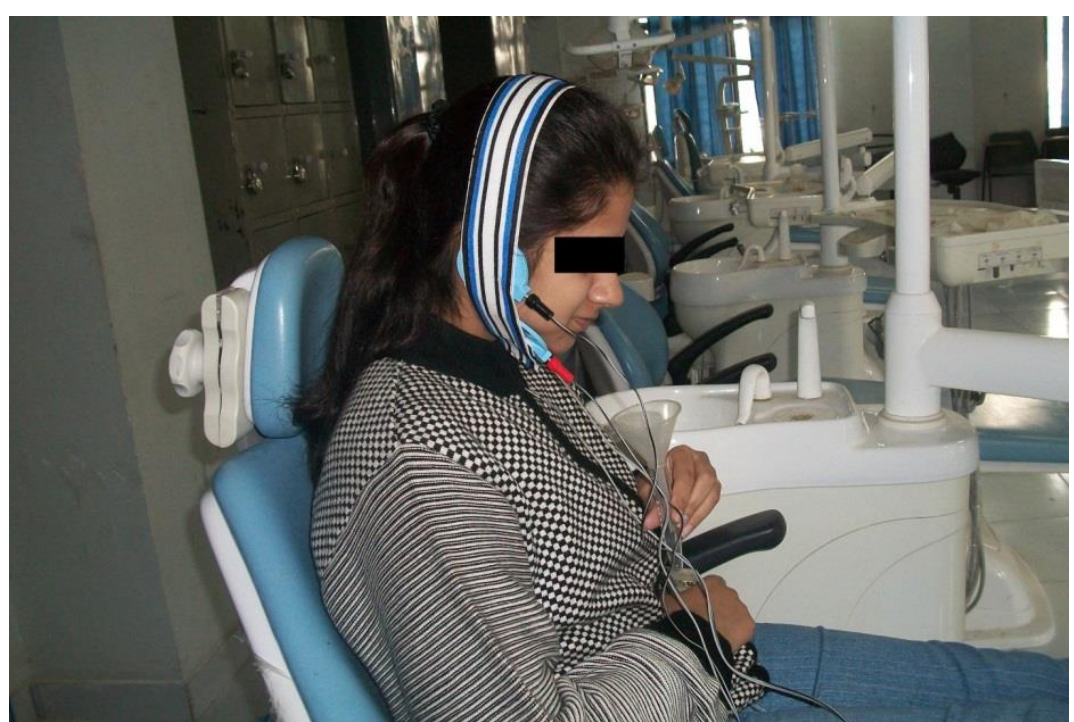

Fig-1: Saliva collection technique showing patient positioning and placement of the surface electrode pads externally overlying the glands with the TENS unit in the "off" position

\section{DISCUSSION}

Saliva plays an important role in oral health monitoring, regulating and maintaining the integrity of the oral tissues [1]. It has many important physiologic functions but medications, radiation therapy, systemic conditions and functional disturbances of salivary glands can decrease the salivary flow leading to xerostomia $[3,5]$. The palliative management for xerostomia includes providing relief of its symptoms with the help of wetting agents and saliva substitutes [3]. But this will provide only temporary relief. Only natural saliva contains all the enzymes and other components essential for normal function and protection. For this reason, salivary stimulation was developed to stimulate the production of whole saliva [15].

The salivary secretion is normally controlled by reflex stimulation with effector nerve impulses traveling along the sympathetic and parasympathetic nerves to the glands. ${ }^{2}$ Parasympathetic stimulation produces copious saliva of low protein concentration whereas sympathetic stimulation produces little saliva but with high protein concentration which may give a sensation of dryness [12]. Neural electrostimulation of salivary gland function, through application of electric current through the oral mucosa, on afferent nerve pathway receptors, has been reported to increase the production of saliva and to reduce the symptoms of xerostomia $[2,16]$. TENS has been evaluated in stimulating salivary flow and it was found to be effective even in patients with xerostomia secondary to radiation therapy for head and neck cancer. However, these studies are very few [16, 17]. In view of the above facts, this study was planned to evaluate the effects of TENS on the whole salivary flow rate in healthy 73 adult subjects.

In the present study, we collected the whole saliva instead of parotid saliva. The whole saliva measurements are simple to perform and are useful as an indicator of general salivary performance. They also provide meaningful information concerning the quantitative aspects of gland function and can be obtained easily in a dental office [18].

A wide range of the unstimulated and stimulated salivary flow was observed in our study (Table 1, Graph 1). This variation of salivary flow rate was similar to the observations made by Yeh et al. [1] and Kedar et al.[2] In our study, the mean salivary flow rate under unstimulated condition was found to be $0.479 \pm 0.152 \mathrm{ml} / \mathrm{min}$ while under stimulated condition it was found to be $0.724 \pm 0.189$ $\mathrm{ml} / \mathrm{min}$, thereby showing a percentage increment of $51.1 \%$. Statistically, the increase was found to be significant $(p<0.001)($ Table 1 , Graph 1). Sixty nine out of seventy three responded positively to TENS therapy. This result was in agreement with the studies conducted by Hargitai et al. in which 15 out of 22 healthy subjects demonstrated significant increase in the parotid salivary flow [3] and Kedar et al. in which 85 out of 100 healthy subjects demonstrated significant increase in the whole salivary flow rate [2]. Similarly, also in a study by Damingo, 6 out of 18 post radiation head and neck cancer patients demonstrated significant increase in the salivary flow during the application of TENS[17].

The mechanism by which the TENS unit worked on the salivary glands is not clear. It is possible that it directly stimulated the auriculotemporal nerve that supplies secretomotor drive to the parotid gland. It is less clear if peripheral stimulation of the gland results in a reflex facilitation of central output from the salivatory nucleus of the medulla. The early investigators of electrostimulation postulated that normal physiologic salivary reflexes are augmented. Salivation is controlled by both sympathetic and parasympathetic efferent nerves. Sympathetic stimulation produces sparse, viscous saliva. In order to electrically stimulate sympathetic salivation, higher frequencies and longer pulse duration is required. On the other hand, electric stimulation of parasympathetic nerves of the salivary glands produces copious amounts of watery saliva at lower frequencies, and it is this voluminous serous saliva of the parotid gland that would be clinically most useful in the management of xerostomia [3]. 
In four patients, the salivary flow was decreased with the application of TENS. This finding was similar to the studies conducted by Kedar et al. in which four patients demonstrated a decreased salivary flow [2] \& Hargitai et al. in which two patients demonstrated a decreased salivary flow [3]. The cause for this may involve the frequency and intensity settings. The stimulus perceived by the brain may be painful and the salivary reflex is enhanced when nociceptive input reaches the brain via trigeminal sensory nuclei. Not all preganglionic parasympathetic fibres are necessarily facilitated; some may be inhibited [3]. In our study, the stimulus was kept optimum, at a tolerable level.

As mentioned in different studies done by Gheezi et al. [11] Percival et al. [5] Tylenda et al.[19] the functional changes in the salivary glands have been reported to be associated with aging; however, there is no evidence to show that xerostomia is likely to result from the aging process. However, in one study, Narhi et al. reported that over a 5 year period, an elderly individual's stimulated salivary flow had significantly decreased [20]. In the present study, it was found that in all the age groups, there was a statistically significant increase in TENS stimulated saliva as compared to unstimulated saliva $(p<0.001)$. The mean salivary flow rate amongst younger age group was significantly higher as compared to older age group under both unstimulated and stimulated conditions $(p<0.05)$ (Table 4, Graph 4).

Further, the study was carried out to compare the salivary flow rates between males and females. The mean salivary flow rate was higher for males as compared to females in both unstimulated and stimulated conditions; however, the difference between the two genders was not significant statistically $(p>0.05)$ (Table 2, Graph 2). This finding was similar to the studies conducted by Kedar et al. [2] and Hargitai et al.[3] The reason for the lower salivary rate in women can be attributed to smaller salivary glands and it may be associated with postmenopausal changes[2]. In one study, Gheezi et al. had shown that there were no significant age and gender differences in the salivary flow rates [11].

The only side effect of the TENS therapy seen in our study was mild twitching of the facial musculature, which was also described by Hargitai et al. [3] and Kedar et al. [2] It was minimal and transient and ceased immediately after the TENS unit was switched off. The main advantage offered by TENS over other non-pharmacologic measures such as chewing gum or citric lozenges is that it is an extraoral device with minimal side effects. It can be used while eating food and it does not affect the normal mastication process. Thus, the salivary production while eating would be beneficial, which is not the case with the intraoral devices [2,3]. Chewing gum bases may need to be avoided in those with temporomandibular disorders; it has had favourable but mixed results in studies [3] Artificial saliva preparations are often objectionable.

\section{CONCLUSION}

The results of this study conclude that the TENS unit was highly effective in stimulating the whole salivary flow rate in healthy adult subjects. Further research of this modality in the stimulation of salivary flow is required to determine its role in the treatment of xerostomic patients secondary to various local and systemic causes. The encouraging results of the present study indicate that TENS has the potential to increase salivary flow and can be a viable alternative in the management of xerostomia when other therapies have failed or are contraindicated.

\section{REFERENCES}

1. Sreebny, L. M. (2000). Saliva in health and disease: an appraisal and update. International dental journal, 50(3), 140-161.

2. Vilas, S. K., Shashikant, M. C., \& Ali, I. M. (2009). Evaluation of the effects of transcutaneous electrical nerve stimulation on whole saliva flow: A clinical study. Journal of Indian Academy of Oral Medicine and Radiology, 21(1), 7.

3. Hargitai, I. A., Sherman, R. G., \& Strother, J. M. (2005). The effects of electrostimulation on parotid saliva flow: a pilot study. Oral Surgery, Oral Medicine, Oral Pathology, Oral Radiology, and Endodontology, 99(3), 316-320.

4. Streckfus, C. F., Brown, L. J., Ship, J. A., \& Brunelle, J. (1993). Stimulated parotid gland flow rates in healthy, elderly dentulous and edentulous individuals. The Journal of prosthetic dentistry, 70(6), 496-499.

5. Percival, R. S., Challacombe, S. J., \& Marsh, P. D. (1994). Flow rates of resting whole and stimulated parotid saliva in relation to age and gender. Journal of dental research, 73(8), 1416-1420.

6. Navazesh, M., \& Kumar, S. K. (2008). Measuring salivary flow: challenges and opportunities. The Journal of the American Dental Association, 139, 35S-40S.

7. Ship, J. A., Eisbruch, A., d'Hondt, E., \& Jones, R. E. (1997). Parotid sparing study in head and neck cancer patients receiving bilateral radiation therapy: one-year results. Journal of dental research, 76(3), 807-813.

8. Närhi, T. O. (1994). Prevalence of subjective feelings of dry mouth in the elderly. Journal of dental research, 73(1), 20-25.

9. Chen, A., WAI, Y., LEE, L., LAKE, S., \& WOO, S. B. (2005). Using the modified Schirmer test to measure mouth dryness: a preliminary study. The Journal of the American Dental Association, 136(2), 164-170.

10. Blom, M., \& Lundeberg, T. (2000). Long-term follow-up of patients treated with acupuncture for xerostomia and the influence of additional treatment. Oral diseases, 6(1), 15-24.

11. Ghezzi, E. M., Lange, L. A., \& Ship, J. A. (2000). Determination of variation of stimulated salivary flow rates. Journal of dental research, 79(11), 1874-1878. 
12. Porter, S. R., Scully, C., \& Hegarty, A. M. (2004). An update of the etiology and management of xerostomia. Oral Surgery, Oral Medicine, Oral Pathology, Oral Radiology, and Endodontology, 97(1), 28-46.

13. Erlichman, M. (1990). Patient selection criteria for electrostimulation of salivary production in the treatment of xerostomia secondary to Sjogren's syndrome. Health technology assessment reports, (8), 1-7.

14. Kararmaz, A., Kaya, S., Karaman, H., \& Turhanoglu, S. (2004). Effect of the frequency of transcutaneous electrical nerve stimulation on analgesia during extracorporeal shock wave lithotripsy. Urological research, 32(6), 411-415.

15. Talal, N., Quinn, J. H., \& Daniels, T. E. (1992). The cilical effects of electrostimulation on salivary function of Sjögren's syndrome patients. Rheumatology international, 12(2), 43-45.

16. Wong, R. K., Jones, G. W., Sagar, S. M., Babjak, A. F., \& Whelan, T. (2003). A Phase I-II study in the use of acupuncture-like transcutaneous nerve stimulation in the treatment of radiation-induced xerostomia in head-and-neck cancer patients treated with radical radiotherapy. International Journal of Radiation Oncology ${ }^{*}$ Biology* Physics, 57(2), 472-480.

17. Domingo, D. L. (2004). The effects of electrostimulation on saliva production in postradiation head and neck cancer patients. Oral Surgery, Oral Medicine, Oral Pathology, Oral Radiology and Endodontology, 4(97), 464.

18. Fox, P. C., Brennan, M., Pillemer, S., Radfar, L., Yamano, S., \& Baum, B. J. (1998). SJOÖGREN'S SYNDROME: A MODEL FOR DENTAL CARE IN THE 21ST CENTURY. The Journal of the American Dental Association, 129(6), 719-728.

19. Tylenda, C. A., Ship, J. A., Fox, P. C., \& Baum, B. J. (1988). Evaluation of submandibular salivary flow rate in different age groups. Journal of dental research, 67(9), 1225-1228.

20. Narhi, T. O., Kurki, N., \& Ainamo, A. (1999). Saliva, salivary micro-organisms, and oral health in the home-dwelling old elderly-a five-year longitudinal study. Journal of dental research, 78(10), 1640-1646. 